\title{
BMJ Open Preliminary study of the relationship between career choice motivation and understanding of professionalism in newly enrolled medical students in China: a cross-sectional study
}

\author{
Xuemei Cui (D) , Ning Ding, Nan Jiang, Honghe Li, Deliang Wen (C)
}

To cite: Cui $X$, Ding $N$, Jiang N, et al. Preliminary study of the relationship between career choice motivation and understanding of professionalism in newly enrolled medical students in China: a crosssectional study. BMJ Open 2021;11:e041860. doi:10.1136/ bmjopen-2020-041860

- Prepublication history and supplemental material for this paper is available online. To view these files, please visit the journal online (http://dx.doi. org/10.1136/bmjopen-2020041860).

Received 28 June 2020 Revised 23 January 2021 Accepted 27 January 2021

Check for updates

(c) Author(s) (or their employer(s)) 2021. Re-use permitted under CC BY-NC. No commercial re-use. See rights and permissions. Published by BMJ.

Institute for International Health Professions Education and Research, China Medical University, Shenyang, Liaoning China

Correspondence to Professor Deliang Wen; dlwen@cmu.edu.cn

\section{ABSTRACT}

Objectives Early professionalism education for first-year students is important for generating sound knowledge and attitudes towards medical professionalism. Of the many factors affecting professionalism and professional identity formation in medical students, career choice motivation is an understudied one. This study aimed to explore the relationship between the career choice motivations of first-year medical students and their understanding of professionalism.

Settings and participants A cross-sectional survey of 940 first-year clinical medicine students was conducted at China Medical University in September 2017 to explore students' motivation to study medicine and its relationship with students' understanding of professionalism. Demographics, career choice motivation and professionalism were obtained through paper questionnaires. Logistic regression analysis was used to analyse the association between career choice motivation and understanding of professionalism while controlling for potential demographic confounders.

Results The most common career choice motivations for first-year medical students $(\mathrm{N}=843)$ were interested in the health sciences, income and social status and advocating altruism. The most mentioned subdimensions of professionalism were accountability, pursuit of excellence and compassion. There were significant differences in the understanding of professionalism among students with different career choice motivations.

Conclusion First-year medical students with different motivations to study medicine also have different understandings of professionalism. Medical educators can explore motivations to learning medicine as a new entry point to providing professionalism education for newly enrolled medical students.

\section{INTRODUCTION}

Professionalism is a core competency that enables healthcare workers to perform their duties, adhere to ethical principles and demonstrate sensitivity to a diverse patient population. ${ }^{1}$ Knowledge and understandings of professionalism have profound influences
Strengths and limitations of this study

- This study specifically focused on medical students in the early stage of the medical school.

- The professionalism was asked with open-ended questions, which helped to minimise the influences caused by fixed questionnaire items.

- Categorical variables were used to allow for logistic regression analysis and to improve the validity and practicality of the results.

- The study was limited by its cross-sectional design, and reflective results were used as key factors, which may affect the generalisability of this study.

- The types of motivations were not collected in a ranked and sequenced way, which made it impossible to determine the relative importance of motivations.

on a medical student's competence, including the formation of professional identity. ${ }^{2}$ When examining 'empathy' as a subdimension of professionalism, ${ }^{3}$ it was discovered that there existed a correlation between medical students' career choice motivations and their empathy. This now begs the questions of whether or not career choice motivations have any relationship with professionalism as a whole. As of the writing of this article, there has been limited evidence on this in the internationally available literature.

From the perspective of humanism, career choice motivation and professionalism share similar factors, but further research is required to understand the relationship between them. Career choice motivation for medical students can be defined as 'the student's motivation for pursuing a medical career when entering medical school'. ${ }^{45} \mathrm{~A}$ review of motivational factors showed that the main motivators to students' selection of medical study in recent years could 


\begin{tabular}{|c|c|}
\hline Variable & n (\%) \\
\hline \multicolumn{2}{|l|}{ Gender } \\
\hline Male & $361(42.82)$ \\
\hline Female & $482(57.18)$ \\
\hline \multicolumn{2}{|c|}{ Duration of the medical programme (years) } \\
\hline 5 & 644 (76.39) \\
\hline 8 & $199(23.61)$ \\
\hline \multicolumn{2}{|l|}{ Household registration area } \\
\hline Rural & $572(67.85)$ \\
\hline Urban & $256(30.37)$ \\
\hline Missing & $15(1.78)$ \\
\hline \multicolumn{2}{|l|}{ Annual household income ( $¥)$} \\
\hline$\leq 20000$ & $171(20.28)$ \\
\hline $20,000-50000$ & $201(23.84)$ \\
\hline $50000-100000$ & $386(45.79)$ \\
\hline$\geq 100000$ & $60(7.12)$ \\
\hline Missing & $25(2.97)$ \\
\hline \multicolumn{2}{|l|}{ Fathers' educational level } \\
\hline Junior high school and below & $265(31.44)$ \\
\hline High school & $255(30.25)$ \\
\hline University degree & $312(37.01)$ \\
\hline Missing & $11(1.30)$ \\
\hline
\end{tabular}

Fathers' occupation*

Legislators, senior officials and managers 171 (20.28)

Professionals, technicians and associate $121(14.35)$ professionals

$\begin{array}{lc}\text { Clerical support workers } & 48(5.69) \\ \text { Service and sales workers } & 117(13.88) \\ \begin{array}{l}\text { Skilled agricultural, forestry and fishery } \\ \text { workers }\end{array} & 103(12.22) \\ \begin{array}{l}\text { Craft and related trades workers, plant } \\ \text { and machine operators and assemblers }\end{array} & 78(9.25) \\ \text { Other } & 192(22.78) \\ \text { Missing } & 13(1.54)\end{array}$

*Based on the International Standard Classification of Occupations $\left(\right.$ ISCO-08) ${ }^{46}$

be categorised into three major dimensions: science, society and humanitarianism. ${ }^{6}$ In addition, motivators for medical students' career choices also included interesting illnesses, opportunities for private practice and patient access. ${ }^{7}$ Students' understanding of professionalism is inseparable from the accumulation of scientific knowledge and the influence of social concepts. ${ }^{8}$ Furthermore, the core of medical humanism involves listening, empathy, communication and other interpersonal skills, ${ }^{9}$ all of which are subdimensions of professionalism as a whole. ${ }^{10}$ Further research is required to understand the relationship between these factors, particularly in various scenarios, environments and populations. To better understand how career choice motivators and initial understanding of professionalism are related, without the influence of professionalism education in medical school, newly enrolled first-year medical students who are at the beginning of their medical careers were favoured as the target study population.

The first year of medical school has proven to be an important period to receive professionalism education and to address any career challenges that may arise. ${ }^{11} \mathrm{~A}$ recent study focused on newly enrolled first-year medical students by Ommering et $a l^{2}$ had suggested that the first year may be a reasonable period for understanding students' motivations. With this in mind, some medical schools have improved students' understanding of professionalism by integrating discussions on professionalism as part of the first-year curriculum. ${ }^{11}$ A study of medical ethics in first-year students suggested that the early days of medical school could be an effective period for developing moral reasoning skills ${ }^{13}$ which was also stressed as an aspect of professionalism.

This study aimed to explore the relationship between the career choice motivations of first-year medical students and their understanding of professionalism. To our knowledge, there has been little research to date on this topic, so this was an exploratory attempt to understand the correlation and to shed light on the cultivation and improvement of medical students' professionalism.

\section{METHODS}

\section{Participants}

All of the 940 first-year clinical medicine students at China Medical University were invited to participate in this study in September 2017. Full instructions were given to students before filling out the three-part questionnaire, following which students completed the questionnaires in the classroom. Participation was voluntary, and all student participants filled out an informed consent form.

\section{Patient and public involvement}

No patient was involved in this study.

\section{QUESTIONNAIRE \\ Demographics}

A demographic questionnaire was used to collect information on participants' sex, household registration area (urban/rural), durations of medical programme, parents' educational levels, parents' occupations and annual household income. The household registration area (urban or rural) is an assigned residence registration system for all Chinese residents on birth or attaining citizenship. ${ }^{14}$ Durations of medical programmes usually comprise two major streams: a 5-year bachelor's degree programme or an 8-year bachelor's and master's combined program. ${ }^{15}$ The questionnaire is shown in online supplemental appendix I.

\section{Career choice motivation}

Career choice motivations of first-year medical students were obtained by means of a single multi-select question, 


\begin{tabular}{lc}
$\begin{array}{l}\text { Table } 2 \\
\text { motivations (N=843) }\end{array}$ & First-year medical students' career choice \\
\hline Career choice motivations & $\mathbf{n}(\%)$ \\
\hline Interest in the health sciences & $399(47.33)$ \\
Income and social status & $385(45.67)$ \\
Advocating altruism & $337(39.98)$ \\
Family member in healthcare & $257(30.49)$ \\
Parents' expectations or illness in the family & $182(21.59)$ \\
Other motivations & $9(1.07)$ \\
\hline
\end{tabular}

where students were able to choose all options that applied. The options were as follows: (1) income and social status, (2) family member in healthcare, (3) advocating altruism (relieve the dying or rescue the wounded), (4) interested in the health sciences, (5) parents' expectations or illness in the family (desire to care for a family member) and (6) other motivations (students were asked to specify). The question on career choice motivation was based on the instrument called 'Career Choice Motivation' by Pagnin et $a l^{5}{ }^{5}$ which referenced the existing theories on motivation. ${ }^{16} 17$

\section{Professionalism}

First-year medical students' understandings of professionalism were obtained using an open-ended question: 'What do you think professionalism in healthcare encompasses?' Using open-ended questions to measure professionalism removed potential ceiling effects that may seriously affect survey results and could more accurately reflect students' true views on professionalism. ${ }^{18}$

Responses were then coded and classified according to the evaluation framework and instrument for the medical professionalism of Chinese physicians. ${ }^{19}$ This professionalism framework was based on CiteSpace cluster analysis of literature on medical professionalism assessment from the past 15 years. The result was four primary dimensions which were then subdivided into seven secondary

\begin{tabular}{|c|c|}
\hline Professionalism dimension & n (\%) \\
\hline \multicolumn{2}{|l|}{ Dimension 1} \\
\hline Compassion & $460(54.57)$ \\
\hline Respectfulness & $102(12.10)$ \\
\hline Collaboration & $142(16.84)$ \\
\hline \multicolumn{2}{|l|}{ Dimension 2} \\
\hline Integrity & $349(41.40)$ \\
\hline Accountability & $655(77.70)$ \\
\hline \multicolumn{2}{|l|}{ Dimension 3} \\
\hline Pursuit of excellence & $532(63.11)$ \\
\hline \multicolumn{2}{|l|}{ Dimension 4} \\
\hline $\begin{array}{l}\text { Fair and ethical stewardship of healthcare } \\
\text { resources }\end{array}$ & $56(6.64)$ \\
\hline
\end{tabular}

dimensions: (1a) compassion, (1b) respectfulness, (1c) collaboration; (2a) integrity, (2b) accountability; (3) pursuit of excellence and (4) fair and ethical stewardship of healthcare resources. It was constructed from the perspective of a systematic framework and was the result of cultural adaptation and validation in Chinese medical students.

\section{Data analysis}

Career choice motivations were collated as dichotomous variables. Four researchers coded students' responses on their understanding of professionalism, which were then mapped to the professionalism framework. ${ }^{19}$ Coders were first required to read and understand the professionalism framework. When uncertainties in coding or classification arose, all coders came into joint discussion until a unanimous decision was reached. For example, the variable accountability was assigned a value of 1 or 0 based on whether or not there was discourse of accountability in the student's response. Each variable was dichotomous in nature ( 1 , if mentioned; 0 , otherwise).

Logistic regression models were used to explore the relationship between first-year students' motivation to study medicine and their understanding of professionalism. From model 1 to model 3, 'career choice motivations', 'individual characteristics' and 'family characteristics' were gradually introduced into the regression in order to observe the influence of control variables on the regression results. Due to the multi-collinearity of both fathers' and mothers' educational levels and occupations, only fathers' characteristics were controlled in the statistical analysis. After the questionnaire was collected, Epidata 3.1 was used for digital data entry. This was done twice to prevent errors. Descriptive statistics were computed for study variables, which were presented as numbers and percentages. Missing data of control variables were filled in via multiple interpolations. All statistical analyses were performed using Stata V.13 (StataCorp), and the level of significance was set at $\mathrm{p}<0.05$ (two tailed).

\section{RESULTS}

A total of 843 first-year medical students completed the questionnaires, yielding a response rate of $89.68 \%$. Nearly $60 \%$ of the respondents in this study were female. The majority (76.39\%) of students belonged to the 5-year clinical medicine programme. Students' fathers' educational levels were evenly distributed and fathers had varying occupations. Annual household incomes were mostly less than $¥ 100000$ (equivalent to about US $\$ 15000$ at the time of this study). Additional baseline characteristics of the participants are shown in table 1.

Table 2 shows the results of first-year students' career choice motivations. Interest in the health sciences (47.33\%), income and social status (45.67\%) and advocating altruism (39.98\%) were main motivators to students choosing to study medicine. Family-related factors such as family member in healthcare and parents' expectations or illness in the 
Table 4 Logistic regression analysis between compassion and career choice motivations $(\mathrm{N}=843)$ Compassion, OR (95\% Cl)

\begin{tabular}{|c|c|c|c|}
\hline \multirow[b]{2}{*}{ Variable } & & & \\
\hline & Model 1† & Model $2 \ddagger$ & Model $3 \S$ \\
\hline Interest in the health sciences & $1.50(1.14 \text { to } 1.99)^{*}$ & $1.44(1.08 \text { to } 1.92)^{\star}$ & $1.43(1.07 \text { to } 1.92)^{\star}$ \\
\hline Income and social status & $0.93(0.71$ to 1.23$)$ & $0.86(0.64$ to 1.14$)$ & $0.87(0.65$ to 1.16$)$ \\
\hline Family member in healthcare & 0.89 (0.66 to 1.2$)$ & 0.89 (0.65 to 1.22$)$ & $0.86(0.63$ to 1.19$)$ \\
\hline Parents' expectations or illness in the family & 0.80 (0.57 to 1.12$)$ & $0.83(0.59$ to 1.17$)$ & 0.85 (0.60 to 1.21$)$ \\
\hline Female & & 1.16 (0.87 to 1.56$)$ & 1.15 (0.86 to 1.55$)$ \\
\hline \multicolumn{4}{|l|}{ Duration of the medical programme (years) } \\
\hline 5 & & 1 & 1 \\
\hline 8 & & $3.27(2.27 \text { to } 4.70)^{*}$ & $2.96(1.95 \text { to } 4.51)^{\star}$ \\
\hline
\end{tabular}

Household registration area

\begin{tabular}{|c|c|c|}
\hline Rural & 1 & 1 \\
\hline Urban & $1.08(0.79$ to 1.47$)$ & $1.25(0.84$ to 1.84$)$ \\
\hline \multicolumn{3}{|l|}{ Annual household income ( $¥)$} \\
\hline$\leq 20000$ & & 1 \\
\hline $20000-50000$ & & $1.69(1.10 \text { to } 2.60)^{*}$ \\
\hline $50000-100000$ & & $1.54(1.02 \text { to } 2.32)^{*}$ \\
\hline$\geq 100000$ & & 2.07 (0.94 to 4.55$)$ \\
\hline \multicolumn{3}{|l|}{ Fathers' educational level } \\
\hline Junior high school and below & & 1 \\
\hline High school & & $1.08(0.72$ to 1.63$)$ \\
\hline University degree & & $1.33(0.82$ to 2.14$)$ \\
\hline \multicolumn{3}{|l|}{ Fathers' occupation } \\
\hline Legislators, senior officials and managers & & 1 \\
\hline $\begin{array}{l}\text { Professionals, technicians and associate } \\
\text { professionals }\end{array}$ & & 1.61 (0.97 to 2.66$)$ \\
\hline Clerical support workers & & $1.83(0.92$ to 3.65$)$ \\
\hline Service and sales workers & & 1.28 (0.75 to 2.19$)$ \\
\hline Skilled agricultural, forestry and fishery workers & & 1.44 (0.75 to 2.78$)$ \\
\hline $\begin{array}{l}\text { Craft and related trades workers, plant and machine } \\
\text { operators and assemblers }\end{array}$ & & 1.34 (0.72 to 2.49$)$ \\
\hline Other & & $1.81(1.09 \text { to } 3.01)^{*}$ \\
\hline
\end{tabular}

${ }^{*} \mathrm{p}<0.05$.

†Only career choice motivation was included.

$\ddagger$ Career choice motivation and individual characteristics were included.

$\S$ Career choice motivation, individual characteristics and family characteristics were included.

family had less influence on students' decisions to study medicine, at $30.49 \%$ and $21.59 \%$, respectively.

First-year medical students' understandings of physician professionalism are shown in table 3 . From student responses, accountability was mentioned by the majority $(77.70 \%)$ of the students. Both compassion $(54.57 \%)$ and pursuit of excellence $(63.11 \%)$ were mentioned by more than half of the students. However, less than $20 \%$ of the students mentioned respectfulness $(12.10 \%)$ or collaboration $(16.84 \%)$ in their answers, and only $56(6.64 \%)$ students mentioned the fair and ethical stewardship of healthcare resources.
To demonstrate the effects of the regression models, table 4 shows the logistic regression between one of the seven dimensions of professionalism, compassion, and motivations to study medicine. Career choice motivations, personal characteristics and family characteristics were gradually introduced into the regression from model 1 to model 3. Regression results showed that students motivated by interest in the health sciences were significantly more likely to think of compassion than other students, and the significance of the regression relationship did not change with the gradual introduction of control variables. In 
model 3, students motivated by an interest in the health sciences were $43 \%$ more likely than other students to mention compassion ( $\mathrm{OR}=1.43 ; 95 \% \mathrm{CI}=1.07$ to 1.92$)$.

Table 5 shows the logistic regression results of all of the dimensions of professionalism and career choice motivations of first-year medical students based on model 3, where personal and family characteristics were controlled. Students whose medical motivation was interest in the health sciences were $43 \%$ more likely to mention compassion $(\mathrm{OR}=1.43 ; 95 \% \mathrm{CI}=1.07$ to 1.92$)$ than others. Students who chose to study medicine because of income and social status or advocating altruism were only about half as likely as other students to mention fair and ethical stewardship of healthcare resources $(\mathrm{OR}=0.49 ; 95 \% \mathrm{CI}=0.27$ to 0.91 and $\mathrm{OR}=0.50 ; 95 \% \mathrm{CI}=0.26$ to 0.96 , respectively). Students who selected parents' expectations or illness in the family as a motivation were $57 \%$ more likely to mention collaboration than other students (OR=1.57; 95\% CI=1.01 to 2.44).

\section{DISCUSSION}

In this study, there was a significant relationship between career choice motivations and understanding of professionalism in Chinese medical students. Logistic regression analysis showed students who chose to study medicine because of interest in the health sciences not only mentioned more dimensions of physician professionalism but mentioned compassion more than others. In terms of fair and ethical management and use of medical resources, both students who were motivated by income and social status and those who were motivated by advocating altruism tended to be half as likely as others to mention this dimension. Students whose medical motivations were family oriented (parents' expectations or illness in the family) were more likely to mention collaboration.

In this study, results did not show any dominant career choice motivation (one which accounted for more than $50 \%$ of students). This may have been because the career choice motivations in this study were obtained through a multi-select questionnaire. Students were able to choose multiple career choice motivations at the same time. In this study, interest in the health sciences was the top motivation of first-year medical students. According to selfdetermination theory, 'interest' belongs to autonomous motivation, which refers to motivation that arises from true interest or personal recognition or attention to an activity. ${ }^{20}$ Studies had pointed out that autonomous motivation was considered to bring better quality of learning, creativity, performance, persistence, resilience, happiness and lifelong learning. ${ }^{21-23}$ At the same time, self-efficacy has proven to be an important factor in motivation. ${ }^{24}$ Self-efficacy may be defined as a person's self-awareness and self-confidence in successfully completing tasks and achieving goals. ${ }^{25}$ People who believe that they can handle all kinds of problems well will choose more challenging goals in life and are more persistent. ${ }^{26}$ These theories show that self-recognised and confident people are more inclined to make choices motivated by interest. ${ }^{27}$ 
In China, medical schools require higher entrance scores than other majors, and these high scores may be linked with higher self-efficacy because of the demonstrated positive correlation between academic performance and self-efficacy ${ }^{28}$ which may then prompt them to value their own interests.

In addition to interest in the health sciences, a relatively higher number of students selected income and social status and advocating altruism as career choice motivations. This was consistent with the trends shown by a Hungarian study, ${ }^{29}$ where although altruism was important, it was not the only consideration for students, and career and status plans also accounted for a large proportion of the motivation. Advances in science and technology brought not only material changes but also the desire to improve quality of life and standards of living. ${ }^{30}$ A summary of career choice motivations pointed out that in some middle-income countries, students would yearn for a better lifestyle and higher income when basic needs have already been met and would be attracted by the sense of security and social respect brought by a career as a doctor. $^{6}$ As such, perhaps what used to be a traditional aspect of medicine (altruism) ${ }^{31}$ now invites major focus in remediation in medical education and medical school admissions.

The most mentioned subdimensions of professionalism were accountability, pursuit of excellence and compassion. A previous study on medical students' perceptions of medical professionalism provided evidence that students' general knowledge of professionalism mainly comprised responsibility and compassion, demonstrating that students can recognise fundamental core values of medical professionalism even at the earliest level of their medical education. ${ }^{32}$ This may be because responsibility and compassion are common aspects of humanism, ${ }^{9}$ which is generally recognised and expected by the society for medical careers. ${ }^{33}$

The pursuit of excellence was defined as 'pursuit of progress, updating knowledge, breaking through difficulties, and lifelong learning awareness' in this framework. ${ }^{19}$ In recent years, students' self-concept and self-directed learning have seen significant improvement, which has been confirmed in international studies on first-year students' understanding of professionalism and professionalism identity formation. ${ }^{32-34}$ Self-concept is defined as the way an individual perceives himself and his potential to evaluate his strengths and weaknesses. ${ }^{35}$ Self-directed learning refers to the process in which students actively diagnose their learning needs, create learning goals, determine learning resources, apply appropriate learning strategies and evaluate their learning outcomes. ${ }^{36}$ Based on the above concepts and their relation to self-awareness, students may be driven to have a more proactive attitude towards what is to be accomplished. Therefore, we can infer that the high rate of mentioning pursuit of excellence may be driven in part by students' self-awareness. For these most-mentioned professionalism dimensions, more encouragement should be given in future medical education to avoid lapses in professionalism that may occur with the accumulation of medical knowledge and the progress of medical practice. ${ }^{37}$

Other dimensions of professionalism, including integrity, respectfulness, collaboration and fair and ethical stewardship of healthcare resources, were mentioned relatively less. These professionalism dimensions that were less recognised by first-year medical students may need to be nurtured through professionalism education. According to students' individual understandings of professionalism, personalised learning may be introduced to meet the differing needs of students. ${ }^{38}$ Medical educators may consider using career choice motivation as an entry point to develop professionalism education programmes.

Students who were motivated by interest in the health sciences mentioned compassion more than others. An overview of self-compassion showed that there is a close relationship between compassion and self-compassion. ${ }^{39}$ Another study of nurses showed that understanding of self-compassion may be a source to compassionate care. ${ }^{40}$ Research has shown that self-compassion may be positively related to intrinsic motivation, which suggests that motivation originates from genuine interest. ${ }^{41}$ Research suggests that self-compassionate individuals tend to experience a greater sense of autonomy and self-determination in their lives. ${ }^{41}$ According to self-determination theory, students who were motivated by interest in the health sciences were those who chose careers according to their interests; they were more self-determined. ${ }^{20}$ Based on this concept, students who were motivated by interest in the health sciences may have had higher levels of self-compassion. Linking theory with evidence from this study, the correlation between students who had interest in the health sciences and students mentioning compassion may be attributed in part to the role of 'self-compassion', which calls for further research in this area.

Students whose medical motivation was parents' expectations or illness in the family demonstrated a higher level of awareness of collaboration. Collaboration was defined in this framework as good cooperation with the medical team and with patients, to communicate to resolve conflicts and complete medical tasks. ${ }^{19}$ Intimate relationships with family members and family support may lay some foundation for a teamwork atmosphere. A study promoting therapeutic alliance between families of patients and research teams showed that collaboration developed through communication between patients and their families, between families and physicians, and among medical teams. ${ }^{42}$ It may be possible that students who were motivated by illness in the family (desire to care for a family member) recognised the importance of collaborative teams in the process of caring for their families and therefore paid more attention to collaboration. For example, in student responses, students mentioned things such as 'a good doctor should keep a good interpersonal relationship with team members and give them emotional support' and 'before medical decision making, physicians should be good at listening to patients'. 
In Maslow's hierarchy of needs, ${ }^{43}$ 'medical resources' may be classified as a basic need. Income and social status belongs to the fourth level: 'the need of respect, prestige, prominence, magnificence, appreciation, attention, status, self-esteem', and advocating altruism belongs to the top level of 'need for self-realisation'. ${ }^{6}$ In this study, students who were motivated by income and social status and who were motivated by advocating altruism demonstrated a lower recognition of fair and ethical management and use of medical resources. Maslow's hierarchy of needs can be used to provide the possible explanation that when high-level needs arise, low-level needs are no longer the dominant needs. ${ }^{43}$ Interestingly, in this study, students who seemingly had contrasting motivations (income and status vs altruism) both tended to mention 'medical health resources' less than others. This suggests that no matter whether or not the value pursuit of students reaches the level of 'self-actualisation', there may be no clear consciousness and opinion on the allocation and use of basic resources. However, the rational allocation and use of resources is crucial in both the healthcare system and the society. Therefore, in medical education, students' management and awareness of medical and health resources should be strengthened.

There were several limitations in our study. This was a cross-sectional study, so causal relationships between firstyear students' career choice motivations and their understanding of professionalism could not be inferred. We recommend further longitudinal research to follow-up and investigate the causal relationship between these two concepts. Another limitation of this study was that we were not able to collect information on the types of motivations in a ranked and sequenced way. The relative importance given to these various motivations by prospective doctors may affect their career choice in the future. ${ }^{44}$ This is something to be improved on in future investigations. On the basis of this study, future work should further explore whether students' career choice motivations would change as their medical studies progress, ${ }^{45}$ and if so, to what extent such changes will affect students' perceptions of medical professionalism.

\section{CONCLUSION}

This study provided evidence that first-year medical students with different motivations to study medicine had different understandings of professionalism. Career choice motivations of medical students could be used as a potential entry point for professionalism education, and interventions and remediation can be adapted to improve medical students' professionalism by customising them based on students' career choice motivations.

Acknowledgements The authors wish to thank China Medical University for authorising the use of the survey data. Special thanks to all the students who have participated in this study.

Contributors DW was responsible for research design. Questionnaire implementation and data analysis were conducted by ND and XC. The final manuscript was written by XC and NJ. Guidance and revision of the manuscript were completed by ND, HL and NJ.

Funding This work was supported by the China Medical University 'the 13th FiveYear' the First Batch of Medical Education Key Projects (No. 3), 'the 13th Five-Year' the First Batch of Medical Education Projects (Grant No. YDJK2016002), and the Natural Science Foundation of Liaoning Province of China (Grant No. 20180550272).

Competing interests None declared.

Patient consent for publication Not required.

Ethics approval All subjects who participated in the survey signed the informed consent form. The study protocol and questionnaire were approved by the China Medical University Ethics Committee.

Provenance and peer review Not commissioned; externally peer reviewed.

Data availability statement The data sharing statement for this study was obtained from an open and regular student survey of China Medical University. Data are available upon reasonable request.

Supplemental material This content has been supplied by the author(s). It has not been vetted by BMJ Publishing Group Limited (BMJ) and may not have been peer-reviewed. Any opinions or recommendations discussed are solely those of the author(s) and are not endorsed by BMJ. BMJ disclaims all liability and responsibility arising from any reliance placed on the content. Where the content includes any translated material, BMJ does not warrant the accuracy and reliability of the translations (including but not limited to local regulations, clinical guidelines, terminology, drug names and drug dosages), and is not responsible for any error and/or omissions arising from translation and adaptation or otherwise.

Open access This is an open access article distributed in accordance with the Creative Commons Attribution Non Commercial (CC BY-NC 4.0) license, which permits others to distribute, remix, adapt, build upon this work non-commercially, and license their derivative works on different terms, provided the original work is properly cited, appropriate credit is given, any changes made indicated, and the use is non-commercial. See: http://creativecommons.org/licenses/by-nc/4.0/.

\section{ORCID iDs}

Xuemei Cui http://orcid.org/0000-0002-0374-9207

Deliang Wen http://orcid.org/0000-0002-4038-3849

\section{REFERENCES}

1 Larkin GL, Binder L, Houry D, et al. Defining and evaluating professionalism: a core competency for graduate emergency medicine education. Acad Emerg Med 2002;9:1249-56.

2 Forouzadeh M, Kiani M, Bazmi S. Professionalism and its role in the formation of medical professional identity. Med J Islam Repub Iran 2018;32:765-8.

3 Chen D, Lew R, Hershman W, et al. A cross-sectional measurement of medical student empathy. J Gen Intern Med 2007;22:1434-8.

$4 \mathrm{Kim} \mathrm{K-J,} \mathrm{Hwang} \mathrm{JY,} \mathrm{Kwon} \mathrm{BS.} \mathrm{Differences} \mathrm{in} \mathrm{medical} \mathrm{students'}$ academic interest and performance across career choice motivations. Int J Med Educ 2016;7:52-5.

5 Pagnin D, De Queiroz V, De Oliveira Filho MA, et al. Burnout and career choice motivation in medical students. Med Teach 2013;35:388-94.

6 Goel S, Angeli F, Dhirar N, et al. What motivates medical students to select medical studies: a systematic literature review. BMC Med Educ 2018;18:16.

7 Lefevre JH, Roupret M, Kerneis S, et al. Career choices of medical students: a national survey of 1780 students. Med Educ 2010;44:603-12.

8 Cruess SR. Professionalism and medicine's social contract with Society. Clin Orthop Relat Res 2006;449:170-6.

9 American Academy of Neurology Ethics, Law, and Humanities Committtee. Humanistic dimensions of professionalism in the practice of Neurology. Neurology 2001;56:1261-3.

10 Janczukowicz J, Rees CE. Preclinical medical students' understandings of academic and medical professionalism: visual analysis of mind maps. BMJ Open 2017;7:e015897.

11 Strobel R, Antunez A, De La Rosa K, et al. Medical professionalism: a series of Near-Peer facilitated workshops for first-year medical students. MedEdPORTAL 2017;13:10549.

12 Ommering BWC, van Blankenstein FM, Waaijer CJF, et al. Future physician-scientists: could we catch them young? factors influencing intrinsic and extrinsic motivation for research among first-year medical students. Perspect Med Educ 2018;7:248-55. 
13 Self DJ, Baldwin DC, Olivarez M. Teaching medical ethics to first-year students by using film discussion to develop their moral Reasoning. Acad Med 1993;68:383-5.

14 Cooney RS, Li J. Household registration type and compliance with the "one child" policy in China, 1979-1988. Demography 1994;31:21-32.

15 Xinyu C, Zhaofeng L. Cooperation of medical education to speed up the establishment of medical personnel training system. Chin J Med Educ Manage 2016;2:321-5.

16 Vallerand RJ, Blais MR, Brière NM. Construction and validation of the scale of motivation in education. Can J Behav Sci 1989;21:323-49.

17 Kusurkar RA, Ten Cate TJ, van Asperen M, et al. Motivation as an independent and a dependent variable in medical education: a review of the literature. Med Teach 2011;33:e242-62.

18 Monrouxe LV, Chandratilake M, Gosselin K, et al. Taiwanese and Sri Lankan students' dimensions and discourses of professionalism. Med Educ 2017;51:718-31.

$19 \mathrm{Li} \mathrm{H}$. Constract the evaluation framework and intrument for the medical professionalism of Chinese physicians and its application [Dissertation]. China Medical Unversity, 2017.

20 Kusurkar RA. Autonomous motivation in medical education. Med Teach 2019;41:1083-4.

21 Ten Cate TJ, Kusurkar RA, Williams GC. How self-determination theory can assist our understanding of the teaching and learning processes in medical education. AMEE guide No. 59. Med Teach 2011;33:961-73.

22 Kusurkar RA, Croiset G. Autonomy support for autonomous motivation in medical education. Med Educ Online 2015;20:27951.

23 van der Burgt SME, Kusurkar RA, Wilschut JA, et al. Motivational profiles and motivation for lifelong learning of medical specialists. J Contin Educ Health Prof 2018;38:171-8.

24 Zimmerman BJ. Self-Efficacy: an essential motive to learn. Contemp Educ Psychol 2000;25:82-91.

25 Locke EA, Bandura A. Social foundations of thought and action: a Social-Cognitive view. Acad Manage Rev 1987;12:169-71.

26 Zimmerman BJ, Kitsantas A. Acquiring writing revision skill: shifting from process to outcome self-regulatory goals. J Educ Psychol 1999;91:241-50.

27 Li Y, Huo T, Zhuang K, et al. Functional connectivity mediates the relationship between self-efficacy and curiosity. Neurosci Lett 2019;711:134442.

28 Hayat AA, Shateri K, Amini M, et al. Relationships between academic self-efficacy, learning-related emotions, and metacognitive learning strategies with academic performance in medical students: a structural equation model. BMC Med Educ 2020;20:76.

29 Györffy Z, Birkás E, Sándor I. Career motivation and burnout among medical students in Hungary - could altruism be a protection factor? BMC Med Educ 2016;16:182.

30 Mahan JD, Clinchot D. Why medical education is being (inexorably) re-imagined and re-designed. Curr Probl Pediatr Adolesc Health Care 2014;44:137-40.
31 Pilowsky I. Altruism and the practice of medicine. Br J Med Psychol 1977;50:305-11.

32 Reimer D, Russell R, Khallouq BB, et al. Pre-clerkship medical students' perceptions of medical professionalism. BMC Med Educ 2019;19:239.

33 Miller SZ, Schmidt HJ. The habit of humanism: a framework for making humanistic care a reflexive clinical skill. Acad Med 1999;74:800-3

34 Holden MD, Buck E, Luk J. Professional identity formation: creating a longitudinal framework through time (transformation in medical education). Acad Med 2015;90:761-7.

$35 \mathrm{Ma}$ X, Kishor N. Attitude toward self, social factors, and achievement in mathematics: a meta-analytic review. Educ Psychol Rev 1997:9:89-120.

36 Knowles MS. Self-directed learning. Englewood Cliffs, NJ: Prentice Hall Regents, 1975.

37 Brennan N, Price T, Archer J, et al. Remediating professionalism lapses in medical students and doctors: a systematic review. Med Educ 2020;54:196-204.

38 Flogie A, Aberšek B, Kordigel Aberšek M, et al. Development and evaluation of intelligent serious games for children with learning difficulties: observational study. JMIR Serious Games 2020;8:e13190

39 Sinclair S, Kondejewski J, Raffin-Bouchal S, et al. Can selfcompassion promote healthcare provider well-being and compassionate care to others? results of a systematic review. Appl Psychol Health Well Being 2017;9:168-206.

40 Wiklund Gustin L, Wagner L, Gustin LW LW. The butterfly effect of caring - clinical nursing teachers' understanding of selfcompassion as a source to compassionate care. Scand J Caring Sci 2013;27:175-83.

41 Neff KD, Hsieh Y-P, Dejitterat K. Self-compassion, achievement goals, and coping with academic failure. Self and Identity 2005;4:263-87.

42 Kalocsai C, Amaral A, Piquette D, et al. "It's better to have three brains working instead of one": a qualitative study of building therapeutic alliance with family members of critically ill patients. $B M C$ Health Serv Res 2018;18:533.

43 Block M. Maslow's hierarchy of needs. Psychol Rev 1943;50:370-96.

44 McManus IC, Livingston G, Katona C. The attractions of medicine: the generic motivations of medical school applicants in relation to demography, personality and achievement. BMC Med Educ 2006;6:11.

45 Del-Ben CM, Shuhama R, Costa MJ, et al. Effect of changes to the formal curriculum on medical students' motivation towards learning: a prospective cohort study. Sao Paulo Med J 2019;137:112-8.

46 Office IL. International standard classification of occupations (ISCO-08), 2012. Available: https://ilostat.ilo.org/resources/methods/ classification-occupation/ 